\title{
Phosphorus recycling and food security in the long run: a conceptual modelling approach
}

\author{
Hans-Peter Weikard ${ }^{1}$ (D) \\ Received: 14 November 2014 / Accepted: 12 January 2016/Published online: 4 February 2016 \\ (C) The Author(s) 2016. This article is published with open access at Springerlink.com
}

\begin{abstract}
Food security for all is a global political goal and an outstanding moral concern. The common response to this concern is agricultural intensification, which includes among other things increasing inputs of fertilisers. The paper addresses the fact that phosphorus $(\mathrm{P})$ is essential for agricultural production but large and increasing amounts of $\mathrm{P}$ fertilisers stem from depletable mines. This raises sustainability concerns and the possibility of long-term food insecurity. The paper analyses three scenarios for global phosphorus extraction and recycling under discounted utilitarianism. First, for a benchmark scenario without recycling, food security will inevitably be violated in the long run. Second, if we introduce P recycling, food security can be maintained but food production falls over time and approaches a minimum level just sufficient to feed the global population. Third, a sustainable (i.e. non-declining) path of food production is feasible. Compared to just maintaining a minimum level of food production the sustainable path requires greater recycling efforts. Recycling efforts are increasing over time but the total discounted costs are finite and, hence, sustainable food production seems feasible even if it depends on depletable phosphate mines.
\end{abstract}

Keywords Phosphorus depletion · Food security · Phosphorus recycling $\cdot$ Sustainable food production

Hans-Peter Weikard

hans-peter.weikard@wur.nl

1 Department of Social Sciences, Wageningen University, Hollandseweg 1, $6706 \mathrm{KN}$ Wageningen, Netherlands

\section{Depletable phosphate mines: impacts for long-run food security}

The well-being of about one billion people is threatened by hunger and food insecurity (FAO 2009). This is arguably a moral disaster and a poor performance of our social and economic systems on the local and the global scale. But even worse, the efforts towards food security are thwarted by population growth and increasing scarcity of agricultural inputs. Notwithstanding efforts to improve food security governance (Pereira and Ruysenaar 2012) a common strategy towards global food security is agricultural intensification with increasing inputs of fertilisers, mainly nitrogen $(\mathrm{N})$, potassium (K) and phosphorus $(\mathrm{P})$ to increase yields (Pinstrup-Andersen and Pandya-Lorch 1998; Baldos and Hertel 2014; PinstrupAndersen 2014). While $\mathrm{N}$ fertilisers can be produced from atmospheric nitrogen (using energy), $\mathrm{K}$ and $\mathrm{P}$ fertilisers are extracted from depletable mines. While $\mathrm{K}$ is relatively abundant, $\mathrm{P}$ is more limited (Scholz and Wellmer 2013). Although the stocks of rock phosphate, the main source of mineral $\mathrm{P}$ fertilizers, are difficult to assess, there is a growing concern that mines might be depleted within a century (Steen 1998; Cordell et al. 2009; Smit et al. 2009; Keyzer 2010; Cordell and White 2015). Although other studies expect sufficient availability beyond the 21st century (van Vuuren et al. 2010; Koppelaar and Weikard 2013), the fact remains that rock phosphate is a depletable resource. ${ }^{1}$ This underlines the need to develop effective and low cost recycling options beyond the application of animal manure and composted organic wastes, the cheap options that are widely applied. Cordell et al. (2011) provide an overview of options for P reuse and recovery. As yet $\mathrm{P}$ recycling from urban wastes, such as for example

\footnotetext{
${ }^{1}$ Ulrich and Frossard (2014) provide a historical perspective on the current debate on $\mathrm{P}$ scarcity.
} 
struvite production from urban waste waters (Cornel and Schaum 2009), is too expensive to be worthwhile, and fertilizers from recycled $\mathrm{P}$ cannot compete with rock phosphates on the market (Molinos-Senante et al. 2011).

The importance and, indeed, the urgency of the phosphorus problem stem from the fact that there is no substitute for $\mathrm{P}$ fertilizers. The productivity of soils is severely hampered if they are P-deficient. A study by Gilland (2006) suggests that a global population of 9 billion - which is the medium projection of the UN Population Division (2004) for 2050 - will be beyond the earth's carrying capacity even if there is no shortage of fertilizers. Kahiluoto et al. (2014) arrive at similar conclusions considering "planetary boundaries". In a business-asusual scenario with continuing agricultural intensification, depletion of phosphorus mines will be inevitable, even if estimates of a "time to depletion" vary by an order of magnitude. Then the intensification of agriculture must come to a halt and soil productivity will decline. The consequences of an increasing scarcity of $\mathrm{P}$ fertilisers are evident from a recent study by Lott et al. (2011) who observed that there have been no improvements in agricultural productivity, for example in large parts of Africa, due to lack of P replenishment. Hence, food production has not kept pace with population growth; see also Cordell and White (2015). When P mines are depleted and there is no recycling, agricultural productivity would be reduced to a level that cannot support a global population of 9 billion (Pimentel et al. 1999). An optimist may point at improved agricultural techniques (e.g. for erosion protection) and technologies (such as improved seeds). Still a gap would remain and the consequences of $\mathrm{P}$ depletion for food security would be severe - at least in the absence of recycling.

This paper develops three scenarios for phosphorus extraction and recycling. The modelling approach draws deliberately on very few stylised facts. In this way the consequences of essentiality and depletability of $\mathrm{P}$ resources can be demonstrated most clearly.

I start with a simple benchmark scenario describing P extraction in a Hotelling model where - on an efficient extraction path - resource extraction must decline and, hence, longrun food security can never be obtained. Food security requires, as a necessary but not sufficient condition, that food production is large enough to meet the nutritional needs of the global population, which in turn requires sufficient $P$ inputs. This underlines the importance of recycling which is the key feature of the second scenario. Here I provide a modified version of the model developed by Weikard and Seyhan (2009). The result is that food security can be maintained but fertilizer use will steadily decline and, in the long-run, food production will approach a minimum level defined by a food security standard. Food production cannot be sustained on an efficient extraction and recycling path. The third scenario is the most relevant and the novelty of this paper. As even today's level of food-security is insufficient, a declining path of $\mathrm{P}$ use (extraction and recycling) cannot be acceptable, unless the persistent food security governance problems are resolved. Therefore, the third scenario, introduces a sustainability constraint for food production. Assuming, for simplicity, a constant technology, I introduce the requirement that food production (and therefore fertilizer input) should never decline. Sustainable food production is feasible and food security can be maintained, at least if its governance does not become worse, but it has its price: Recycling efforts are greater than without a sustainability constraint, and they will always increase.

If sustainable food production is a policy goal, ultimately aiming at non-declining levels of food security, an unregulated market will not achieve this. The analysis of the third scenario suggests that sustaining food security requires governmental intervention, for example a tax on P extraction and subsidies for recycling.

The purpose of this paper is largely conceptual, with the aim of comparing the principal consequences of business-asusual (no recycling), the use of recycling options in a conventional setting (discounted utilitarianism) and extraction and recycling under a sustainability constraint. The model results show the feasibility of sustainable food security even if fertilizer resources are depletable. For this purpose the model is constructed in the simplest possible way that still captures the main features of the phosphorus problem.

The paper's structure matches this line of argument. The second section introduces the benchmark and the "conventional' recycling scenario. In the third section I derive the optimal extraction and recycling paths under a sustainability constraint for food security. As the model is focused on few essential features of the phosphorus problem, some important details of the $\mathrm{P}$ chain from mining to agriculture to consumption and to waste are discussed in the next section. The final section of the paper discusses policy implications and concludes.

\section{A Hotelling model of $P$ extraction}

This section presents the main model features and results in an intuitive way. Mathematical derivations are relegated to an Appendix. I develop three scenarios.

Scenario 1: no recycling I start the analysis assuming a competitive mining industry. For this benchmark model I assume that $\mathrm{P}$ stocks are known and firms maximise discounted returns from mining. To keep the model simple and tractable and in order to focus on the effects of recycling I assume zero extraction cost. In this setting individual firms do not have market power and on the equilibrium extraction path each firm is indifferent between extraction and conservation of an additional unit of $\mathrm{P}$ (Hotelling 1931). Selling an additional ton of $\mathrm{P}$ and reinvesting the profits at the going interest rate $\delta$ must, in 
equilibrium, yield the same payoffs as conservation in order to sell it later. Hence, the rate of change of the value of the resource must equal the rate of interest. Hotelling (1931) showed that the equilibrium price path that prevails in a competitive market economy maximises the discounted welfare of society. In other words, a well-functioning resource market achieves an efficient outcome and a competitive market implements the utilitarian optimum, at least in its common version as discounted utilitarianism. For a depletable resource, utilitarian calculus yields the result that the rate of change of marginal social welfare must equal the discount rate. Denoting welfare by $W$, resource extraction by $x$ and the discount rate by $\delta$, we can write the necessary condition for the welfare optimum as

$\delta=\frac{\dot{W}_{x}}{W_{x}}$

where $W_{x}$ is the (marginal) welfare that accrues from one additional unit of extraction. I write time derivatives with a dot on the variable. Equation (1) is the simplest format of Hotelling's rule. It is a differential equation which says that marginal welfare is growing at a constant rate $\delta$. Over time the resource becomes scarcer and its value grows.

Assuming, in the following, that welfare comprises benefits from the use of a resource and the costs of producing it, I adopt a logarithmic instantaneous benefits function, $\ln \left(x_{t}-\bar{x}\right)$, that is increasing and concave in resource use $x_{t}$ and is characterised by a strictly positive minimum use level, denoted $\bar{x}$, as introduced in Seyhan et al. (2012) to capture the essentiality of $\mathrm{P}$ use for food production and food security. Because $\mathrm{P}$ fertilizer is an essential input for food production, a strictly positive minimum $\mathrm{P}$ use reflects the minimum food requirements of the population. ${ }^{2}$ A shortfall of resource availability below the minimum level would cause disaster and, in the model, the benefits function is no longer well-defined. As resource use approaches the minimum level (from above), marginal benefits rise without limits and the resource becomes infinitely valuable in the limit. In other words, quite obviously, food is most valuable for a population close to starvation.

Since I assume zero extraction cost, the first scenario is described by the following welfare maximisation problem.

$\max _{x_{t}}\left\{W=\int_{0}^{\infty} e^{-\delta \mathrm{t}} \ln \left(x_{t}-\bar{x}\right) \mathrm{d} t\right\}$, subject to $\int_{0}^{\infty} x_{t} \mathrm{~d} t \leq X_{0}$.

\footnotetext{
${ }^{2}$ Dawson and Hilton (2011) calculate a global human nutritional P requirement between 1.7 and 3.7 Mt. P/year which is about $10 \%$ of the $\mathrm{P}$ extracted from mines (Koppelaar and Weikard 2013), indicating some slackness in the chain of $\mathrm{P}$ flows. A discussion of recent issues in the measurement of food security can be found in Gabbert and Weikard (2001) and Weikard and Gabbert (2010).
}

The constraint in (2) says that the sum of extractions at all times cannot exceed the initial stock of the resource $X_{0}$.

The solution to this problem gives

$\delta=-\frac{\dot{x}}{x-\bar{x}}$.

This implies a falling extraction path. Figure 1 shows the optimal extraction for a given minimum use requirement $\bar{x}$ (solid line). The resource stock will be depleted after a finite time $T$. For the special case when $\bar{x}=0$ (dotted line) the rate of change of extraction is constant and equal to $-\delta$. The areas below the extraction paths correspond to the initial size of the resource stock $X_{0}$.

The first result can be now be stated.

RESULT 1 If P from depletable mines is the only source of fertilizer, the equilibrium $P$ extraction path will be (i) declining, (ii) the rate of decline will be falling, (iii) no given strictly positive level of food production can be maintained and food security will inevitably be violated in the long run.

This completes our benchmark scenario. Next we turn to recycling.

Scenario 2: recycling The need for $\mathrm{P}$ recycling stems from three facts. (i) P levels in soils are depleted through erosion and harvest, but must be maintained to preserve soil productivity; (ii) there is no substitute for P; and (iii) P fertilizer supply from rock phosphates cannot be maintained in the long run. There are a number of feasible measures to reduce P loss along the chain from mining to food consumption. Examples are erosion protection and recycling of agricultural and urban wastes. Erosion protection, while very important, is not further discussed as it is the focus of a large strand of literature (e.g. Powlson et al. 2011). Here, let us assume that the utmost has been done for erosion protection and the recycling of crop residues and animal manure within the agricultural system. These recycling measures determine the need for $\mathrm{P}$ replenishment of agricultural soils. Simply put, they determine the productivity of the system, i.e. food production per unit of fertilizer supply from external sources. As noticed by Dasgupta and Heal (1979, p.212) recycling at a given rate would not solve the problem of depletability. Its effect is similar to having a larger stock, but this stock is still finite and Result 1 still applies.

Next, consider losses from harvest. Harvest - and the P it contains - is largely transported to the urban centres, consumed as food and enters the sewage systems as human excreta. In many countries urban waste water is hardly treated (Scott et al. 2004) and where it receives treatment, the P-rich wastes are hardly recovered as they are contaminated with 
Fig. 1 Extraction paths with (solid line) and without (dotted line) a minimum use level $\bar{x}$

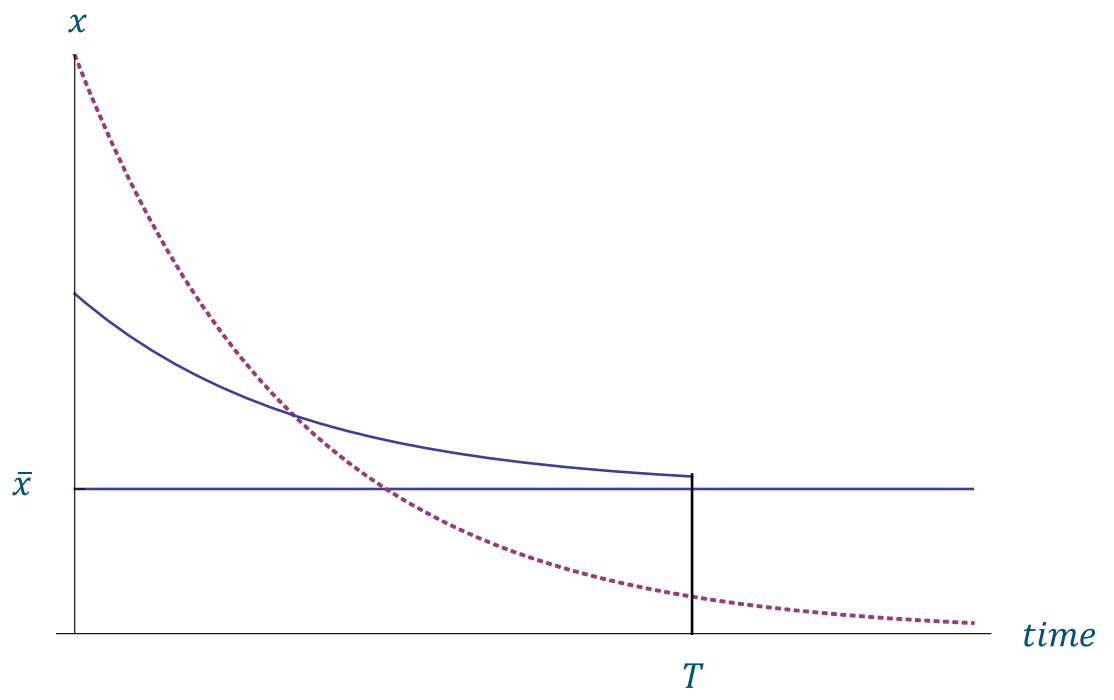

heavy metals (Lundin et al. 2004). This is where recycling technologies, like struvite production from urban waste waters, attain their essential role. Currently new technologies are under development or in the implementation phase (Cornel and Schaum 2009). Hence, in what follows I will assume that the recycling sector can produce suitable fertilizers that are perfect substitutes for fertilizers from rock phosphates. Denote by $x$ the primary and by $y$ the recycled resource such that total resource use (i.e. fertilizer application) at time $t$ is $x_{t}+y_{t}$. The benefits function is

$B_{t}=\ln \left(x_{t}+y_{t}-\bar{x}\right)$.

Again extraction costs are assumed to be zero, but I introduce recycling costs that increase in $y$, decrease in $x$ and increase without limit as the recycling rate $\frac{y}{(x+y)}$ approaches 1 . These are intuitive requirements as it is more costly to recycle larger amounts, it is cheaper to recycle from a larger flow of waste and it impossible to recycle the entire flow without loss. The arguably simplest recycling cost function satisfying these properties is

$R_{t}=\alpha \frac{y}{x}$,

where $0<\alpha<1$ is a scaling parameter. ${ }^{3}$

To find the optimal path of extraction and recycling we need to solve the following welfare maximisation problem:

$\max _{x_{t}, y_{t}}\left\{W=\int_{0}^{\infty} e^{-\delta t}\left(B_{t}-R_{t}\right) \mathrm{d} t\right\}$, subject to $\int_{0}^{\infty} x_{t} \mathrm{~d} t \leq X_{0}$.

\footnotetext{
${ }^{3}$ See Weikard and Seyhan (2009) for a more detailed discussion.
}

The solution to problem (6) is derived in the Appendix. The results can be summarised as follows:

RESULT 2 Under discounted utilitarianism with recycling (i) the extraction path is falling and approaches zero in the long run. (ii) Resource use is complemented by recycled fertilizer. Amounts recycled are also falling and are approaching the minimum use level $\bar{x}$ in the long run.

This result implies an ever increasing recycling rate approaching 1 . Therefore recycling costs increase without limit. Figure 2 shows the extraction path (lower solid line), the recycling path (dotted line) and the total use path (upper solid line).

Clearly, declining resource use in the long run implies declining food production which is approaching its minimum level. The next section explores the prospects for sustainable, that is non-declining, food production.

\section{$P$ extraction and recycling under sustainable food security}

As I have shown in the previous section, the benchmark scenario, where a minimum level of resource use and food security cannot be maintained, can be avoided if a recycling technology is available. But still, both extraction and recycling are declining over time and total $\mathrm{P}$ use will approach the minimum level in the long run. Hence, it is interesting to examine whether resource use and, therefore, food production and food security, can be sustained in the long run. As rock phosphate resources are finite and extraction must inevitably decline in the long run, sustainable $\mathrm{P}$ use requires larger recycling efforts compared to the efficient path under discounted utilitarianism, 
Fig. 2 Time paths for extraction (lower solid line), recycling (dotted line) and total use (upper solid line). The minimum use level is $\bar{x}$

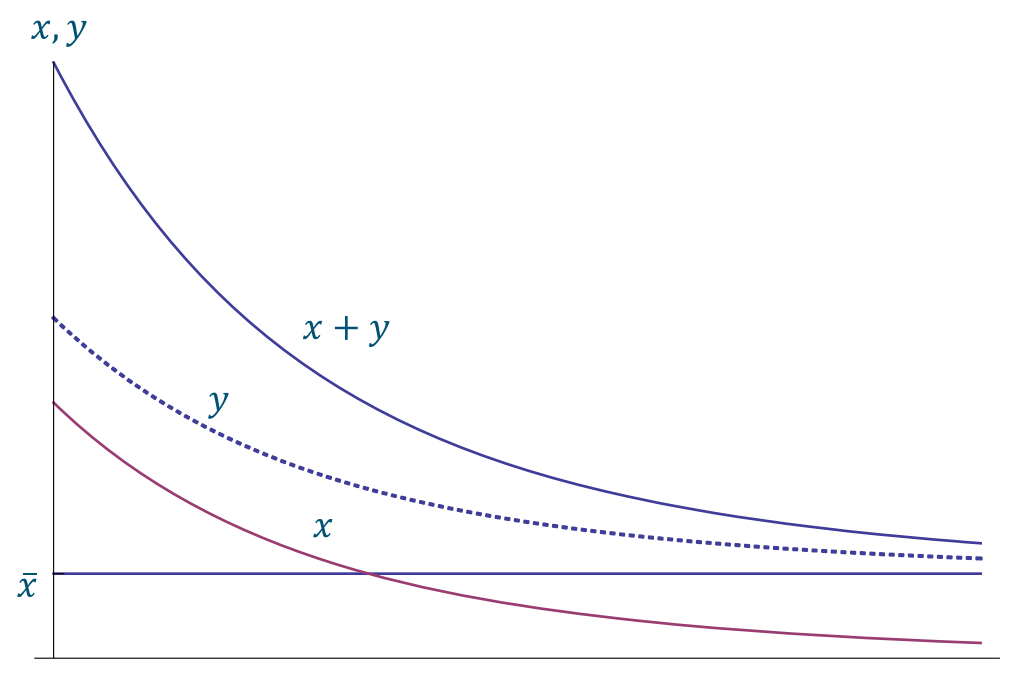

the path of Fig. 2. Recycling must compensate for the declining extraction. Consequently, not only must the recycling rate rise but its rise must be stronger than in the case without a sustainability requirement. I will now examine in detail how extraction and recycling must develop over time if the level of resource use is to be maintained in the long run.

In order to approach this problem formally I proceed in two steps. First let us fix the use level to be sustained at $s \equiv x_{t}+y_{t}>\bar{x}$ and solve for the optimal extraction-recycling combination satisfying the given and fixed resource use level $s$. The second step is to determine the welfare maximising level of sustainable resource use. Notice that, for a given $s$, we can write $y_{t}=s-x_{t}$. The maximization problem we need to solve is as follows:

$\max _{x_{t}}\left\{W=\int_{0}^{\infty}\left(B(s)-R_{t}\right) e^{-\delta t} \mathrm{~d} t\right\}$, subject to $\int_{0}^{\infty} x_{t} \mathrm{~d} t \leq X_{0}$,

where $R_{t}=\alpha \frac{s-x_{t}}{x_{t}}$ and $B(s)$ is a constant.

We find (see Appendix) that the rate of change of extraction is constant and it is one half of the rate of change of extraction that we find for the case when $x=0$ in Scenario 2. Formally,

$\frac{\dot{x}}{x}=-\frac{1}{2} \delta$.

This gives an exponentially declining extraction path,

$x_{t}=x_{0} e^{-\frac{1}{2} \delta \mathrm{t}}$.

The initial extraction $x_{0}$ is implicitly determined by the resource constraint $\int_{0}^{\infty} x_{t} \mathrm{~d} t \leq X_{0}$. Extraction is falling at a lower rate such that the extraction path is flatter than in Scenario 2. More of the resource is saved for later in order to reduce future recycling costs while resource use is always sustained.
The next step is to determine the utilitarian best level of sustained resource use. To do this we employ (9) to solve

$\max _{s}\left\{W=\int_{0}^{\infty}\left(B(s)-\alpha\left(\frac{s^{-} x_{t}}{x_{t}}\right)\right) e^{-\delta \mathrm{t}} \mathrm{d} t\right\}$.

We find (see Appendix) that the optimal level of sustainable resource use $s$ is

$s^{*}=\frac{\delta}{4} X_{0}+\bar{x}$.

Summarising the result:

RESULT 3 The optimal level of sustainable resource use is (i) increasing in initial stock size and (ii) increasing in the discount rate. (iii) It is strictly larger than the minimum use level $x$ for any positive stock of the resource and any positive discount rate.

Part (i) of this result is obvious. With larger stocks, recycling efforts and the associated costs can be lower and a higher level of sustainable resource use $s$ is optimal. The intuition for the (perhaps surprising) part (ii) of the result is that a higher sustainable use comes at higher recycling costs that are increasing over time. A lower discount rate gives a higher weight to future recycling costs. Thus with a lower discount rate, a lower level of sustainable resource use is preferred. Notice that, because we are looking at a sustainable path of resource use, benefits are constant over time such that the discount rate only drives the intertemporal allocation of costs. Figure 3 shows extraction and recycling for two different discount rates.

The analysis of extraction and recycling paths reveals two effects. First, the recycling rate is growing and approaching 1 in the long run. Second the amount recycled is growing. This 


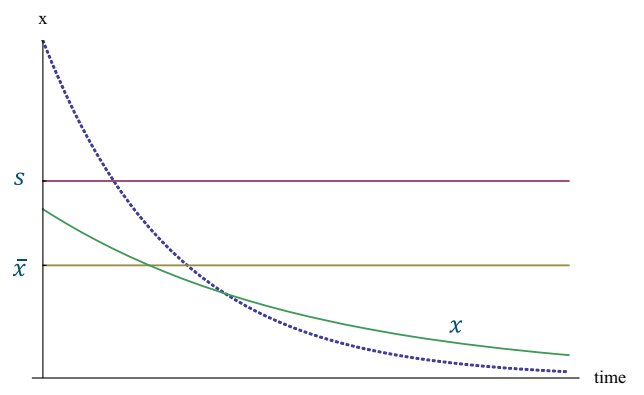

Fig. 3 Extraction paths (solid line) for a low (left panel) and a high (right panel) discount rate for optimal sustainable resource use $s$. The minimum use level is $\bar{x}$. For comparison the dotted lines show the Hotelling

is an important difference from Scenario 2 where the amount recycled is declining. Sustainable food production and, by implication, sustainable food security, requires growing inputs of recycled fertilizer. Before, I have assumed that costs of recycling are increasing and convex in the recycling rate. As extraction is falling over time, we have to recycle more and at larger unit costs to sustain fertiliser inputs. This implies that recycling costs rise strongly and without limits as the recycling rate approaches 1 . The feasibility of sustainable food production will then depend on whether (rising) recycling costs can be covered in a (growing) economy. To address this issue I show in the Appendix that discounted recycling costs are falling over time and that the net present value of the total recycling costs is finite, see Appendix. Discounting puts a weight on future costs that falls exponentially over time. Although costs are rising, they rise less strongly than the weight falls. Note that discounting reflects circumstances where factors of production (here: extraction and recycling) are more readily available in the future (Weikard and Zhu 2005). The finding that discounted recycling costs are falling is important as it underlines the general feasibility of sustainable food production and food security.

\section{Management implications along the $P$ chain}

The scenarios above are analysed with simplified models. The paper is not concerned with particular P management options, but derives the importance of $\mathrm{P}$ recycling for food security from a small number of facts where essentiality and depletability are key.

In this section I want to discuss policy implications. For each and every model, whether simple or complex, model outcomes depend on assumptions. Hence, policy implications cannot be spelled out without a discussion of model assumptions. I will discuss these assumptions along the $\mathrm{P}$ chain from extraction to food consumption and to waste flows. I will briefly discuss the five main components of the chain: (i) mining, (ii) agriculture and soils, (iii) consumption, (iv) sewage systems and (v) surface waters and the ocean.

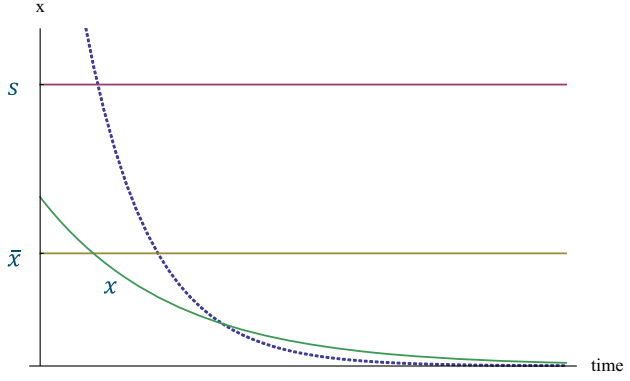

extraction paths for the respective benchmark scenario. Recycled amounts are the difference between resource use $s$ and the amount extracted

Mining Rock phosphate resources are highly concentrated in a few countries with the largest reserves in Morocco, Western Sahara and China (Table 1). This implies that most countries and among them the countries with the highest rates of food insecurity must rely on P imports. The highly concentrated supplies make the access to $\mathrm{P}$ rock resources a geopolitcal issue, an issue that constitutes another motive for a resources policy that strengthens recycling (Cordell and White 2015). Also with only few mining companies involved, the market may not be fully competitive as assumed in the model. If mining companies have market power, they will restrict supplies to drive up prices as analyses of natural resource cartels suggest (e.g. Berg et al. 1997). This would result in delayed extraction compared to a competitive market. A second simplification is the neglect of extraction costs and production costs of fertilizer. These costs are driven by the state of technology and by the quality of the resource stocks. High quality stocks are those with easy access, high concentration of $\mathrm{P}$ in the rocks and low concentrations of heavy metals that must be removed in the fertilizer production process. The impact of resource quality and technological change on the resource extraction path is ambiguous. Seyhan et al. (2012) showed that extraction can be non-declining with falling resource prices in an initial phase. At later stages, however, prices will

Table 1 Estimated phosphate production and reserves for $2010[\mathrm{Mt}$ rock phosphates]*

\begin{tabular}{lll}
\hline Country & Mine production & P reserves \\
\hline Algeria & 2 & 2200 \\
China & 65 & 3700 \\
Jordan & 6 & 1500 \\
Morocco and Western Sahara & 26 & 50,000 \\
South Africa & 2 & 1100 \\
U.S.A. & 26 & 1400 \\
Other & 49 & 4800 \\
World total & 176 & 65,000 \\
\hline
\end{tabular}

Source: U.S. Geological Survey (2011)

*Rock phosphates contain on average about $30 \% \mathrm{P}_{2} \mathrm{O}_{5}$ 
rise and extraction will decline. This suggests that market prices may not function well as scarcity indicators for resources. Even in a phase of declining market prices the in situ value (the shadow price) of the resource will be increasing.

Agriculture and soils The benefits of $P$ fertilizers stem from improved agricultural productivity. The agricultural production process is modelled using a simple logarithmic function. While this simplifies the analysis, the crucial role of agriculture in long term P management must be emphasised. First, agriculture does not just produce market crops but also animal products like meat, milk and eggs. Animals produce manure used as fertilizer as a coupled product. Hence an important issue is to keep internal agricultural $\mathrm{P}$ cycles intact, or restore them where they are disrupted. This includes also, for instance, proper management of crop residues. Schröder et al. (2011) discuss various options to improve agricultural $\mathrm{P}$ management in more detail; see also Reijnders (2014) for a survey. The most important set of measures are those addressing soil erosion, which is responsible for a significant fraction of $\mathrm{P}$ losses. A second issue is the role of soils as $\mathrm{P}$ stocks and buffers (Lott et al. 2011). Intensification of agriculture has led to $\mathrm{P}$ saturated soils in many developed countries while large parts of the world including large parts of Africa suffer from $P$ deficient soils (MacDonald et al. 2011). The consequences of these differences for $\mathrm{P}$ use in the long term are discussed by Weikard and Seyhan (2009).

Our simplified model implicitly assumes direct links between $\mathrm{P}$ inputs, agricultural production, food consumption and food security. But, of course, these links are not simple but complex. Each link would require a separate module to capture details. The link between $\mathrm{P}$ inputs and production could use a production function approach and the link between production and consumption must consider losses in the food chain due to storage and transport.

Consumption Turning to consumption, the two most relevant issues for P flows are waste and the choice of diet. With respect to waste comparable data across countries are missing. For the United States Suh and Yee (2011) estimate that a quarter of the P contained in food purchases is wasted. Metson et al. (2012) argue that dietary choices of consumers also impact $\mathrm{P}$ use. They show that increasing P-use is associated with an increasing consumption of animal products. Thus consumption of meat and milk is less P-efficient than a vegetarian diet. Simply put, the former uses grains as feed while these could be consumed directly.

Finally, the link between food production and food security is 'distorted' by an unequal distribution of consumption. Even if food production is sufficient to meet the nutritional needs of the population, the available food is usually not distributed according to food needs such that the poor do not have access to food even if it is available (Gabbert and Weikard 2001).
Clearly food availability is a necessary but not a sufficient condition for food security. But we can assume that larger availability will generally ease the access to food through lower prices.

Sewage systems Suh and Yee (2011) estimate (for the U.S.) that about $15 \%$ of the $\mathrm{P}$ used as fertilizer is contained in human food intake. This part ends up in the sewage system and is, jointly with other organic waste, the target of the most important recycling options. The model assumes a simple recycling function that neglects, for example, the role of technological progress. Recycling technologies for $\mathrm{P}$ are in their early stages of development and are likely to improve over time. Furthermore, with low rates of waste water treatment in many developing countries (cf. Scott et al. 2004) large scale $P$ recycling from waste water is difficult at, least in the shortterm. It requires major investments and careful treatment systems design (Gengenbach and Weikard 2012).

Surface water and the ocean $\mathrm{P}$ is a pollutant in surface waters and the ocean. Our model does not take any pollution damage directly into account. However, recycling reduces pollution which implies that we have recycling benefits that exceed the benefits from fertilizer production (MolinosSenante et al. 2011). Hence, the social cost of recycling will be lower than the private costs.

\section{Conclusions for resource policies}

With these brief comments and disclaimers in mind I can now turn to the discussion of policy options. There are two key areas for policy intervention: extraction and recycling. Our discussion starts from the assumption that sustainable food security is a policy goal of primary importance. This suggests that $\mathrm{P}$ losses along the $\mathrm{P}$ chain, such as losses through erosion and food waste, should be reduced. The general formulation of the model of this paper allows for a comprehensive interpretation of "recycling" that may include erosion protection measures and efficiency improvements in the food chain. If we go beyond the cheap recycling options in agriculture, the adequate use of animal manure and crop residues, the essence of recycling is, however, $\mathrm{P}$ recovery from waste water. In industrialised countries, where (almost) all waste water is treated, the task is to recover P from sewage sludge. While this is technically feasible, the costs are an order of magnitude higher than those for P fertilizers from rock phosphates; see Molinos-Senante et al. (2011) for more details. The problem of $\mathrm{P}$ recycling is worse in developing countries where waste water receives little or no treatment. Hence, P recovery is particularly expensive where it is needed most, such as, for example, in many African countries with $\mathrm{P}$ deficient soils (Cordell et al. 2009). We have seen from our analysis that food 
security cannot be sustained in the long run if depletable mines are the only source of P. For practical policy purposes the "long run" can be anything between 50 and 500 years. No matter which of the estimates is adopted, the depletability of mines makes recycling essential and subsidies to the recycling sector seem to be justifiable. Such subsidies would also help to reduce the costs of surface water pollution. At the same time, research to improve technologies and to lower the cost of $\mathrm{P}$ recovery from waste should be supported. It is essential to stimulate innovation in the recycling sector in order to make recycled $\mathrm{P}$ competitive. As long as this is not the case (and in the absence of direct recycling subsidies or equivalent measures) $\mathrm{P}$ recycling will be postponed until $\mathrm{P}$ prices, which will rise over time, have reached the level of marginal recycling costs. At that time, however, the remaining stock of $\mathrm{P}$ and, therefore, the optimal level of sustainable $\mathrm{P}$ consumption will be smaller.

A second and perhaps even more important area of policy intervention is the extraction sector. As mines are privately owned and mine owners can be assumed to maximise the (discounted) profits from extraction, the equilibrium price path must satisfy Hotelling's rule. This means that, in the absence of extraction costs, the price of $\mathrm{P}$ must rise at the discount rate $\delta$ in the market equilibrium. In our simple setting where extraction costs and stock effects are absent this implies that the extraction path is declining at rate $\delta$, as in Scenario 2 with a zero minimum use level. Compared with this situation the decline of extraction must slow down under a sustainable food security constraint (Scenario 3). The optimal extraction path is found to decline at rate $\frac{1}{2} \delta$, such that extraction is postponed to the future. It is evident, then, that the market does not implement optimal sustainable food security. Mine owners extract the resource too quickly. An obvious policy option is to regulate extraction directly for example by introducing an extraction quota that falls with rate $\frac{1}{2} \delta$ over time. An alternative is a resource tax that is falling over time such that the mine owners' after-tax revenues for extraction rise with the discount rate. Such tax schemes were suggested, although in a different context, by Long and Sinn (1985). Notice that the implementation of both policy measures requires global cooperation, or at least the cooperation of the major Pexporting countries.

To conclude, current $\mathrm{P}$ flows and their future development are driven by agricultural intensification. There are many possible interventions in the $\mathrm{P}$ chain such as improvements in mining or agricultural $\mathrm{P}$ management. Here the focus is on recycling. The main conclusion from Scenario 3 that considers a sustainable food security constraint is that we should stretch out the extraction of $\mathrm{P}$ resources over time in order to operate with lower recycling rates and reduce recycling costs in the long run. Three types of policy interventions seem to be appropriate: subsidies to recycling, subsidies to research and technological development in the recycling sector, and taxes or quota in the mining sector. Notice that, contrary to intuition, the tax rate must fall over time although the resource becomes increasingly scarce.

There is an obligatory note of caution, however. This paper explores a simple model, leaving aside many important details. The policy conclusions I draw should therefore be read as a heuristic, indicating a direction for further applied modelling and scenario analysis.

Acknowledgments The paper was presented at the 20th Annual Conference of the European Association of Environmental and Resource Economists (2013) and at the 4th Sustainable Phosphorus Summit (2014) where I received thoughtful comments. I wish to thank two anonymous reviewers and the Editor-in-Chief for their suggestions to improve the paper.

\section{Appendix}

This Appendix offers a formal treatment of the optimal extraction and recycling problem for an essential resource. We start with the case of conventional discounted utilitarianism and introduce a sustainability constraint in a second step.

We solve

$$
\begin{gathered}
\max _{x_{t}, y_{t}}\left\{W=\int_{0}^{\infty} e^{-\delta \mathrm{t}}\left(B_{t}-R_{t}\right) \mathrm{d} t\right\}, \text { subject to } \\
\dot{X}_{t}=-x_{t} \text { and } \int_{0}^{\infty} x_{t} \mathrm{~d} t \leq X_{0} .
\end{gathered}
$$

We use optimal control to solve this dynamic optimisation problem. ${ }^{4}$ We adopt the specifications in (4) and (5). This gives the (current value) Hamiltonian function as $H=\ln (x+y-x)-\alpha \frac{y}{x}-\lambda x$ and we obtain the following first order necessary conditions:

$$
\begin{aligned}
& \frac{\partial H}{\partial x}=0=\frac{1}{x+y-\bar{x}}+\alpha \frac{y}{x^{2}}-\lambda \Rightarrow \lambda=\frac{1}{x+y-\bar{x}}+\alpha \frac{y}{x^{2}} \\
& \frac{\partial H}{\partial y}=0=\frac{1}{x+y-\bar{x}}-\alpha \frac{1}{x}
\end{aligned}
$$

$$
-\frac{\partial H}{\partial X}=\dot{\lambda}-\delta \lambda \Rightarrow \delta=\frac{\dot{\lambda}}{\lambda}
$$

Taking time derivatives of (12) and substituting in (14) gives

\footnotetext{
${ }^{4}$ The reader who is not familiar with this technique may consult Chiang (1992) or Sydsæter et al. (2008).
} 
$\delta=-\frac{2 \frac{\dot{x}}{x} \bar{x}+\frac{1}{\alpha} \dot{x}}{\bar{x}+\frac{1}{\alpha} x}$

The solution of the differential Eq. (15) gives the extraction path for a given resource constraint $\int_{0}^{\infty} x_{t} \mathrm{~d} t \leq X_{0}$. The path is drawn in Fig. 2. Solving (13) for $y$ we find

$y=\left(\frac{1}{\alpha}-1\right) x+\bar{x}$

Figure 2 also shows the recycling path.

Next, consider a sustainability constraint for food production. The Hamiltonian function for problem (7) is $H=B(s)-\alpha \frac{s-x}{x}-\lambda \mathrm{x}$. The first order necessary conditions are

$$
\begin{aligned}
& \frac{\partial H}{\partial x}=0=\alpha \frac{x+\left(s^{-x}\right)}{x^{2}}-\lambda \Rightarrow \lambda=\alpha \frac{s}{x^{2}} \\
& -\frac{\partial H}{\partial X}=\dot{\lambda}-\delta \lambda \Rightarrow \delta=\frac{\dot{\lambda}}{\lambda} .
\end{aligned}
$$

Taking time derivatives of (17) and substituting in (18) gives

$-\frac{\dot{x}}{x}=\frac{1}{2} \delta$

This establishes that extraction is falling at a constant rate $\frac{1}{2} \delta$. We can write the constraint as $\int_{0}^{\infty} x_{0} e^{-\frac{1}{2} \delta \mathrm{t}} \mathrm{d} t \leq X_{0}$. Integration and solving for $x_{0}$ gives $x_{0}=\delta \frac{X_{0}}{2}$. Notice that the extraction path is independent of the minimum use level $\bar{x}$. For a given level $s$ the recycling path is determined by $y_{t}=s-\delta \frac{X_{0}}{2} e^{-\frac{1}{2} \delta t}$.

Next we use these results to determine the optimal level of sustainable use, i.e. we solve problem (10). Integrating out the objective function in (10) gives

$W=\frac{1}{\delta} \ln (s-\bar{x})-\frac{\alpha}{\delta}\left(1+\frac{2 s}{x_{0}}\right)$.

The first order necessary condition gives:

$0=\frac{1}{\delta} \cdot \frac{1}{s-x}-\frac{2 \alpha}{\delta x_{0}} \Leftrightarrow s=\frac{x_{0}}{2 \alpha}+\bar{x}$.

Substituting $x_{0}=\delta \frac{X_{0}}{2}$ we obtain $s=\frac{X_{0}}{4 \alpha} \delta+\bar{x}$.

Finally, we take a closer look at recycling costs. We assume that the sustainability constraint is binding such that $x_{0}<s$ and (strictly positive) recycling is necessary form the start. The discounted recycling costs at $t$ are
$R_{t} e^{-\delta \mathrm{t}}=e^{-\delta \mathrm{t}} \alpha\left(\frac{s}{x_{t}}-1\right)=\alpha\left(\left(\frac{1}{2 \alpha}+\frac{2 \bar{x}}{\delta X_{0}}\right) e^{-\frac{1}{2} \delta \mathrm{t}}-e^{-\delta \mathrm{t}}\right)$

Clearly, these costs are positive whenever $s>x_{0}$ which is equivalent with our assumption. Discounted costs are declining and approaching zero in the long run such that the total discounted recycling costs are finite,

$\int_{0}^{\infty} R_{t} e^{-\delta \mathrm{t}} \mathrm{d} t<\infty$

This can be checked by substituting the right hand side of (22) into (23).

Open Access This article is distributed under the terms of the Creative Commons Attribution 4.0 International License (http:// creativecommons.org/licenses/by/4.0/), which permits unrestricted use, distribution, and reproduction in any medium, provided you give appropriate credit to the original author(s) and the source, provide a link to the Creative Commons license, and indicate if changes were made.

\section{References}

Baldos, U. L. C., \& Hertel, T. W. (2014). Global food security in 2050: the role of agricultural productivity and climate change. Australian Journal of Agricultural and Resource Economics, 58(4), 554-570.

Berg, E., Kverndokk, S., \& Rosendahl, K. E. (1997). Gains from cartelisation in the oil market. Energy Policy, 25, 1075-1091.

Chiang, A. C. (1992). Elements of dynamic optimization. New York: McGraw-Hill.

Cordell, D., \& White, S. (2015). Tracking phosphorus security: indicators of phosphorus vulnerability in the global food system. Food Security, 7, 337-350.

Cordell, D., Drangert, J.-O., \& White, S. (2009). The story of phosphorus: global food security and food for thought. Global Environmental Change, 19, 292-305.

Cordell, D., Rosemarin, A. S., Schröder, J. J., \& Smit, A. L. (2011). Towards global phosphorus security: a systems framework for phosphorus recovery and reuse options. Chemosphere, 84(6), 747-758.

Cornel, P. K., \& Schaum, C. (2009). Phosphorus recovery from wastewater: needs, technologies and costs. Water Science and Technology, 59(6), 1069-1076.

Dasgupta, P., \& Heal, G. (1979). Economic theory and exhaustible resources. Cambridge: Cambridge University Press.

Dawson, C. J., \& Hilton, J. (2011). Fertiliser availability in a resourcelimited world: production and recycling of nitrogen and phosphorus. Food Policy, 36(Suppl. 1), S14-S22.

Food and Agriculture Organization of the United Nations (2009). The state of food insecurity in the world. Rome: FAO.

Gabbert, S., \& Weikard, H.-P. (2001). How widespread is undernourishment? A critique of measurement methods and new empirical results. Food Policy, 26(3), 209-228.

Gengenbach, M., \& Weikard, H.-P. (2012). Modelling the urban water chain: incentives and cost recovery for wastewater treatment in developing countries. Urban Water Journal, 9(3), 149-160. 
Gilland, B. (2006). Population, nutrition and agriculture. Population and Environment, 26, 1-16.

Hotelling, H. (1931). The economics of exhaustible resources. Journal of Political Economy, 39, 137-175.

Kahiluoto, H., Kuisma, M., Kuokkanen, A., Mikkilä, M., \& Linnanen, L. (2014). Taking planetary nutrient boundaries seriously: can we feed the people? Global Food Security, 3(1), 16-21.

Keyzer, M. (2010). Towards a closed phosphorus cycle. De Economist, $158,411-425$.

Koppelaar, R., \& Weikard, H.-P. (2013). Assessing phosphate rock depletion and phosphorus recycling options. Global Environmental Change, 23, 1454-1466.

Long, N. V., \& Sinn, H.-W. (1985). Surprise price shifts, tax changes and the supply behaviour of resource extracting firms. Australian Economic Papers, 24, 278-289.

Lott, J. N. A., Kolasa, J., Batten, G. D., \& Campbell, L. C. (2011). The critical role of phosphorus in world production of cereal grains and legume seeds. Food Security, 3, 451-462.

Lundin, M., Olofsson, M., Pettersson, G. J., \& Zetterlund, H. (2004). Environmental and economic assessment of sewage sludge handling options. Resources, Conservation and Recycling, 41, 255-278.

MacDonald, G. K., Bennett, E. M., Potter, P. A., \& Ramankutty, N. (2011). Agronomic phosphorus imbalances across the world's croplands. Proceedings of the National Academy of Sciences, 108(6), 3086-3091.

Metson, G. S., Bennett, E. M., \& Elser, J. J. (2012). The role of diet in phosphorus demand. Environmental Research Letters, 7. doi:10. 1088/1748-9326/7/4/044043.

Molinos-Senante, M., Hernandez-Sancho, F., Sala-Garrido, R., \& Garrido-Baserba, M. (2011). Economic feasibility study for phosphorus recovery processes. Ambio, 40, 408-416.

Pereira, L. M., \& Ruysenaar, S. (2012). Moving from traditional government to new adaptive governance: the changing face of food security responses in South Africa. Food Security, 4, 41-58.

Pimentel, D., Bailey, O., Kim, P., Mullaney, E., Calabrese, J., Walman, J., Nelson, F., \& Yao, X. (1999). Will limits of the earth's resources control human numbers? Environment, Development and Sustainability, 1, 19-39.

Pinstrup-Andersen, P. (2014). Contemporary food policy challenges and opportunities. Australian Journal of Agricultural and Resource Economics, 58, 504-518.

Pinstrup-Andersen, P., \& Pandya-Lorch, R. (1998). Food security and sustainable use of natural resources: a 2020 vision. Ecological Economics, 26, 1-10.

Powlson, D.S., Gregory, P.J., Whalley, W.R., Quinton, J.N., Hopkins, D.W., Whitmore, A.P., Hirsch, P.R., \& Goulding, K.W.T (2011). Soil management in relation to sustainable agriculture and ecosystem services. Food Policy, 36, S72-S87.

Reijnders, L. (2014). Phosphorus resources, their depletion and conservation, a review. Resources, Conservation and Recycling, 93, 32-49.

Scholz, R. W., \& Wellmer, F. W. (2013). Approaching a dynamic view on the availability of mineral resources: what we may learn from the case of phosphorus? Global Environmental Change, 23, 11-27.

Schröder, J. J., Smit, A. L., Cordell, D., \& Rosemarin, A. (2011). Improved phosphorus use efficiency in agriculture: a key requirement for its sustainable use. Chemosphere, 84(6), 822-831.
Scott, C., Faruqui, N.I., \& Raschid, L. (2004). Wastewater use in irrigated agriculture: management challenges in developing countries, in: C. Scott, N.I. Faruqui, \& L. Raschid, eds., Wastewater use in irrigated agriculture-livelihood and environmental issues, CABI/IWMI/ CRDI, Wallingford, UK.

Seyhan, D., Weikard, H.-P., \& van Ierland, E. C. (2012). An economic model of long-term phosphorus extraction and recycling. Resources Conservation and Recycling, 61, 103-108.

Smit, A. L., Bindraban, P. S., Schröder, J. J., Conijn, J. G., \& van der Meer, H. G. (2009). Phosphorus in agriculture: global resources, trends and developments. In Report 282. Plant Research International: Wageningen.

Steen, P. (1998). Phosphorus availability in the 21 st century. Management of a non-renewable resource. Phosphorus \& Potassium, 217 (September-October), 25-31.

Suh, S., \& Yee, S. (2011). Phosphorus use-efficiency of agriculture and food system in the US. Chemosphere, 84, 806-813.

Sydsæter, K., Hammond, P., Seierstad, A., \& Strøm, A. (2008). Further mathematics for economic analysis (2nd ed., ). Harlow, England: FT Prentice Hall.

U.S. Geological Survey (2011). Mineral commodity summaries, January 2011. (http://minerals.usgs.gov/minerals/pubs/commodity/ phosphate rock/mcs-2011-phosp.pdf, accessed 20 April 2015).

Ulrich, A. E., \& Frossard, E. (2014). On the history of a reoccurring concept: phosphorus scarcity. Science of the Total Environment, 490, 694-707.

United Nations Population Division (2004). World population 2300. UN: United Nations. New York.

van Vuuren, D. P., Bouwman, A. F., \& Beusen, A. H. W. (2010). Phosphorus demand for the 1970-2100 period: a scenario analysis of resource depletion. Global Environmental Change, 20, 428-439.

Weikard, H.-P., \& Gabbert, S. (2010). On the measurement of food insecurity: how to account for risk? Journal of Hunger and Environmental Nutrition, 5(2), 254-273.

Weikard, H.-P., \& Seyhan, D. (2009). The distribution of phosphorus resources between rich and poor countries: the effect of recycling. Ecological Economics, 68, 1749-1755.

Weikard, H.-P., \& Zhu, X. (2005). Discounting and environmental quality: when should dual rates be used? Economic Modelling, 22, 868-878.

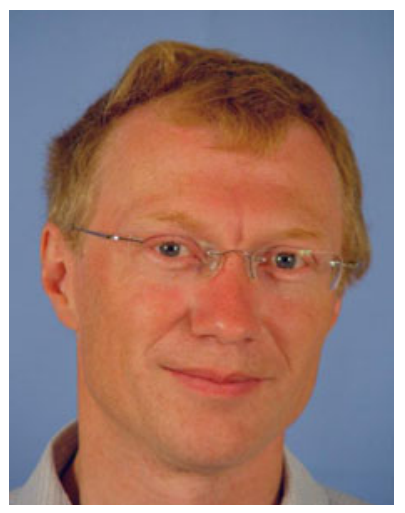

Hans-Peter Weikard studied agriculture, economics and philosophy at the University of Göttingen, Germany. Currently he is an Associate Professor at Wageningen University, the Netherlands, affiliated with the Department of Social Sciences. His research interests comprise social choice, resource economics, risk analysis and the measurement of poverty and food insecurity. 